\title{
Research on the Construction of the Quality Evaluation Model of Graduate Thesis Based on Evidence Theory
}

\author{
Yan $\mathrm{Li}$ \\ School of Information Management \& Engineering, Shanghai University of Finance and Economics, Chain \\ Department of Economics, Huaihua College, Hunan Province, China
}

\begin{abstract}
Objective and fair evaluation of graduate students' theses is a key link in the cultivation of graduate students. The evaluation work of the dissertation is actually a multi attribute group decision making problem. This paper constructs a new model for the quality evaluation of postgraduate degree thesis. The evidence theory is introduced into the evaluation of the degree thesis, and a method based on the evidence theory is proposed to fuse the evaluation information of the experts, so as to make the evaluation work more objective and fair.
\end{abstract}

Keywords-evidence; theory; multi-attribute decision; information fusion

\section{INTRODUCTION}

Postgraduate degree thesis is a scientific research result after the accumulation of knowledge, scientific experiment and theory. It is the comprehensive embodiment of the research ability, innovation ability and written expression ability of the graduate student. Is also an important manifestation of the level of high level innovative talents training in China and the main basis for the degree granting standards? In recent years, the number of graduate students is increasing year by year, and the type of cultivation is gradually diversified. To establish an objective, fair, scientific and reasonable evaluation model is one of the important guarantees to improve the overall quality of graduate students. In recent years, the research of this problem has been concerned by some experts and scholars. In the literature [4]-[1], the index system of the quality evaluation of the graduate thesis is studied. In the literature [8]-[5], the model of the evaluation of the graduate thesis is studied. In the literature [9], the fairness in the evaluation of the graduate degree thesis is studied and some pertinent suggestions are put forward. There are two important aspects to evaluate the quality of the thesis: (1) set the evaluation index system, determine the weights of each index; (2) how to assess each index value and the evaluation value fusion, so as to obtain the comprehensive evaluation results. This paper focuses on the latter problem. The evidence theory is introduced into the evaluation of the thesis. When the expert review to disagree, construct model of information fusion based on evidence theory. Fusion of the assessment expert review comments. Finally, the feasibility of the evaluation model is illustrated by the case.

\section{CONSTRUCt Evaluation MODEL}

\section{A. Evaluation Index System}

In this paper, the evaluation index system and the weight value of each index are shown in table (1):

TABLE I. QUALITY EVALUATION INDEX SYSTEM

\begin{tabular}{|c|c|c|}
\hline & First order index & Two order index \\
\hline \multirow{7}{*}{$\begin{array}{c}\text { Quality } \\
\text { evaluation } \\
\text { index system }\end{array}$} & \multirow{2}{*}{$\begin{array}{l}\text { Thesis topic } \\
\text { selection } \\
\text { and Literature } \\
\text { review }(0.20)\end{array}$} & $\begin{array}{l}\text { Theoretical significance or } \\
\text { practical value of the thesis } \\
\qquad(0.6)\end{array}$ \\
\hline & & $\begin{array}{l}\text { Review and sum up of the } \\
\text { subject and related fields }(0.4)\end{array}$ \\
\hline & \multirow{2}{*}{$\begin{array}{c}\text { Paper } \\
\text { achievement and } \\
\text { Innovative } \\
(0.60)\end{array}$} & $\begin{array}{l}\text { The innovation of the theory or } \\
\text { method } \\
(0.6)\end{array}$ \\
\hline & & $\begin{array}{c}\text { Creative achievement and its } \\
\text { significance } \\
(0.4)\end{array}$ \\
\hline & \multirow{3}{*}{$\begin{array}{l}\text { Theoretical basis, } \\
\text { professional } \\
\text { knowledge and } \\
\text { scientific research } \\
\text { ability } \\
(0.20)\end{array}$} & $\begin{array}{l}\text { Theoretical basis and } \\
\text { professional knowledge }(0.4)\end{array}$ \\
\hline & & $\begin{array}{l}\text { This paper reflects the author's } \\
\text { ability to engage in scientific } \\
\text { research independently. } \\
(0.4)\end{array}$ \\
\hline & & $\begin{array}{l}\text { Writing and summarizing } \\
\text { refining capacity }(0.2)\end{array}$ \\
\hline
\end{tabular}


Note: the construction of the evaluation index system and the determination of the weight value of each index refer to the literature [4] and [5].

\section{A. Structure Evaluation Information Fusion Algorithm}

Assuming that $A=\left\{A_{1}, A_{2}, \cdots, A_{n}\right\}$ is a pending review paper set, $V=\left\{V_{1}, V_{2}, V_{3}\right\}=\{$ topic and review, achievements and innovation, theoretical basis, professional knowledge and research ability $\}$ as the first level evaluation index set, $v_{i}$ is the two level index set of the first level index $V_{j}$, Said any one of the indicators in the two level index set $v_{i}$ as sub indicators to the first level indicators $V_{j}$, Assuming a collection of $B=\left\{B_{1}, B_{2}, \ldots B_{m}\right\}$ as a collection of experts. The expert use of four linguistic evaluation scale system $\mathrm{S}=$ \{excellent, good, qualified and failed $\}=\left\{s_{1}, s_{2}, s_{3}, s_{4}\right\}$ to evaluate the pending review paper. Note $S_{j k i h}$ as the evaluation value of the on paper $A_{k}$ obtained from expert $B_{j}$, according to two indicators $v_{i h}$ of the first level indicators. The weight value of the first level index $v_{1}, v_{2}, v_{3}$ is $\omega_{1}, \omega_{2}, \omega_{3}$, respectively, and the weight value of the one or two level indicators is shown in table (2).

TABLE II. WEIGHT VALUE OF INDEX

\begin{tabular}{|c|c|c|}
\hline \multirow{4}{*}{$\begin{array}{c}\text { weight value of } \\
\text { Index }\end{array}$} & $\omega_{1}=0.2$ & $\omega_{11}=0.6$ \\
\cline { 2 - 3 } & $\omega_{2}=0.6$ & $\omega_{12}=0.4$ \\
\cline { 2 - 3 } & \multirow{3}{*}{$\omega_{3}=0.2$} & $\omega_{22}=0.6$ \\
\cline { 2 - 3 } & $\omega_{31}=0.4$ \\
\cline { 2 - 2 } & $\omega_{32}=0.4$ \\
& $\omega_{33}=0.2$ \\
\hline
\end{tabular}

B. Construction of Information Fusion Model Based on Evidence Theory

Evidence theory is based on the theory of probability. An extension of events in probability theory into propositions. Extending the set of events into a set of propositions. And some concepts such as basic reliability allocation, reliability function and likelihood function are proposed. Establishes a one-to-one correspondence between the proposition and the set, and then transforms the uncertainty of the proposition into the uncertainty of the set.

Definitions 1. (Basic Probability Assignment) Assuming that $\Theta$ is a recognition framework, Consists of a set of mutually exclusive and exhaustive propositions we need to study. Corresponding to the identification framework $\Theta$, a set Function $X: 2^{\Theta} \rightarrow[0,1]\left(2^{\Theta}\right.$ is the power set of the set $\left.\Theta\right)$ is met:

$$
X(\phi)=0
$$

$$
\sum_{\theta \subseteq \Theta} X(\theta)=1
$$

Then $X$ is called basic probability assignment to identification frame $\Theta, \forall \theta \subset \Theta, X(\theta)$ as the basic credible number. Indicates the extent to which the evidence supports the proposition $\theta$. In the function $X, X(\Theta)$ indicates that this probability value is not given to any subset. No information provided. So it is used to express the expression of unknown information.

In this paper, $\Theta$ is excellent, good, qualified, and poor . They are represented by $\left\{\theta_{1}, \theta_{2}, \theta_{3}, \theta_{4}\right\}$.

Dempster synthesis rules of evidence theory:

Assuming that $X_{1}$ and $X_{2}$ are the basic reliability allocation on the same recognition framework $\Theta$. Bel And $\mathrm{Bel}_{2}$, respectively, are two of their corresponding reliability functions. Coking yuan respectively $A_{1}, A_{2}, \quad \ldots \quad, A_{K} \quad$ and $\quad B_{1}, B_{2}, \quad \ldots \quad, B_{L}$. Set $k=\sum_{A_{i} \cap B_{j}=\phi} X_{1}\left(A_{i}\right) X_{2}\left(B_{j}\right)<1$, then the function that is defined by the following type: $X: 2^{\Theta} \rightarrow[0,1]$ is the basic reliability allocation.

$$
X(\theta)=\left\{\begin{array}{cc}
0 & \theta=\phi \\
(1-k)^{-1} \sum_{A_{i} \cap B_{j}=\theta} X_{1}\left(A_{i}\right) X_{2}\left(B_{j}\right) & \theta \neq \phi
\end{array}\right.
$$

This is the S - D synthesis formula, given by the reliability function $X$, known as $\mathrm{Bel}_{1}$ and $\mathrm{Bel}_{2}$ straight and. Remember as $\mathrm{Bel}_{1} \oplus \mathrm{Bel}_{2}$. $(1-k)^{-1}$ As the normalization factor. The normalized factor is to avoid, in evidence combination, non probabilistic normed zero to the empty set. The reliability allocation of empty discarded according to the proportion of compensation to non empty set. Indicates the degree of conflict between the evidence, the greater the value of the conflict, the greater the conflict between the evidence. The synthesis formula of several reliability functions can be derived according to the definition of the synthesis of two belief functions.

Discount rate: due to a basic credibility distribution, can not reflect the whole of the evidence of certain special uncertainty, so a basic credibility of the distribution of $X: 2^{\Theta} \rightarrow[0,1]$ is not clear. The evidence that we only $\alpha$ of plausibility, it satisfies $0 \leq \alpha \leq 1$. The size of the parameter 
$\alpha$ reflects the discount rate of the decision makers on the evaluation results.

Key indicators: the assumption that the index group $u_{1}, u_{2}, \ldots, u_{r}$ has a common parent index, the maximum value is the key indicator, and the rest is non key indicators.

Key indicators and non key indicators of discount rate relationship:

Let's assume that $\omega_{k}=\max \left(\omega_{1}, \omega_{2}, \ldots, \omega_{r}\right)$, the $u_{k}$ index is the key indicators. Index $u_{k}$ is assumed discount rate of $\alpha_{i}$, the discount rate for the non key indicator $u_{i}(i=1, \ldots, k-1, k+1, \ldots, r)$ is $\alpha_{i}=\left(\frac{\omega_{i}}{\omega_{k}}\right) \alpha_{i}$.

Support function: assuming the state $\theta_{j}$, the probability of $u_{i}(i=1,2, \ldots, r)$ index is $\lambda_{i j}$. Using $\ell_{i j}=\alpha_{i} \lambda_{i j}$, said the decision maker, the indicator $u_{i}$ support for the status of $\theta_{j}$.

\section{EMPIRICAL ANALYSIS}

Assuming a total of ten experts to review a graduate degree thesis. Evaluation information of the experts can be expressed as follows: three matrixes.

$$
\begin{aligned}
& D_{1}=\left(\begin{array}{cccc}
0 & 0.6 & 0.4 & 0 \\
0.1 & 0.6 & 0.3 & 0
\end{array}\right) \\
& D_{2}=\left(\begin{array}{cccc}
0.2 & 0.5 & 0.3 & 0 \\
0 & 1 & 0 & 0
\end{array}\right) \\
& D_{3}=\left(\begin{array}{cccc}
0 & 0.2 & 0.7 & 0.1 \\
0 & 1 & 0 & 0 \\
0 & 1 & 0 & 0
\end{array}\right)
\end{aligned}
$$

Matrix $D_{1}$ said, in the first level indicators selected topics and review of the two sub indicators, the theoretical significance or practical value of the topic". There are six experts rated "good"". There are four experts rated as "qualified"'. On the subject and related areas of the review or summary index, there is an expert assessment of excellence, there are six experts rated as good, there are three experts as qualified". The meaning of the remaining two matrices and so on. Review of related or summary," one expert rated "excellent", six experts rated as "good", there are three experts rated "qualified". The meaning of the remaining two matrices and so on.

Fusion evaluation information
Below with the index "selected topic and summary" as an example. The evaluation information of the two sub indexes is fused.

The evaluation information is shown in the following table:

TABLE III. WEIGHT VALUE

\begin{tabular}{|c|c|c|c|c|c|}
\hline Factor & $\begin{array}{c}\text { Weight } \\
\text { value }\end{array}$ & excellent & good & pass & Fail \\
\hline$V_{11}$ & 0.6 & 0 & 0.6 & 0.4 & 0 \\
\hline$V_{12}$ & 0.4 & 0.1 & 0.6 & 0.3 & 0 \\
\hline
\end{tabular}

According to the weight value of the index, the index $v_{11}$ can be determined as the key index. We take the $\alpha_{11}=0.9$ as the discount rate of a key indicator $v_{11}$. The discount rate of non key indicators $v_{12}$ is $\left(\frac{\omega_{12}}{\omega_{11}}\right) \alpha_{11}=\left(\frac{0.4}{0.6}\right) \times 0.9$.The basic reliability distribution of the two sub indexes $v_{11}$ and $v_{12}$ of the index $v_{1}$ can be expressed by the following matrix:

$$
M_{1}\left(v_{1}\right)=\left(\begin{array}{ccccc}
0 & 0.54 & 0.36 & 0 & 0.1 \\
0.06 & 0.36 & 0.18 & 0 & 0.4
\end{array}\right)
$$

Then using the D-S synthesis formula, fuse the synthetic support function of the two sub index $v_{11}$ and $v_{12}$ of the index $v_{1}$, get a basic reliability allocation $X_{1}$ (four decimal places):

$$
X_{1}\left(\theta_{1}\right)=0.0083, X_{1}\left(\theta_{2}\right)=0.6207, X_{1}\left(\theta_{3}\right)=0.2653,
$$

$$
X_{1}\left(\theta_{4}\right)=0, X_{1}(\Theta)=0.1057
$$

In the same way:

$$
\begin{gathered}
X_{2}\left(\theta_{1}\right)=0.0986, X_{2}\left(\theta_{2}\right)=0.6164, X_{2}\left(\theta_{3}\right)=0.1479, \\
X_{2}\left(\theta_{4}\right)=0, X_{2}(\Theta)=0.1371 \\
X_{3}\left(\theta_{1}\right)=0, X_{3}\left(\theta_{2}\right)=0.8938, X_{1}\left(\theta_{3}\right)=0.0861, \\
X_{1}\left(\theta_{4}\right)=0.0117, X_{1}(\Theta)=0.0129
\end{gathered}
$$

So far, we got the basic reliability allocation of index $v_{1}, v_{2}, v_{3}$. Can be expressed by the following matrix: 


$$
M=\left(\begin{array}{cccc}
0.0083 & 0.6207 & 0.2653 & 0 \\
0.0986 & 0.6164 & 0.1479 & 0 \\
0 & 0.8938 & 0.0816 & 0.0117
\end{array}\right)
$$

According to the weight value of the index $v_{1}, v_{2}, v_{3}$, it can be known that the index $v_{2}$ is the key index, and the $v_{1}$ and $v_{3}$ are the key indexes. We take $\left(\frac{\omega_{1}}{\omega_{2}}\right) \alpha_{2}=\left(\frac{0.2}{0.6}\right) \times 0.9=0.3$ as the discount rate of a key indicator $v_{1}$; take $\left(\frac{\omega_{1}}{\omega_{2}}\right) a_{2}=\left(\frac{0.2}{0.6}\right) \times 0.9$ as the discount rate of a key indicator $v_{3}$.

With the discount rate. The line, multiply each ling of the matrix. We can get the following matrix:

$$
m=\left(\begin{array}{ccccc}
0.0025 & 0.1862 & 0.0796 & 0 & 0.7317 \\
0.0590 & 0.3700 & 0.0887 & 0 & 0.4823 \\
0 & 0.2681 & 0.0244 & 0.0035 & 0.7040
\end{array}\right)
$$

D-S formula was used to synthesize, and the comprehensive evaluation results were obtained:

$$
\begin{gathered}
X\left(\theta_{1}\right)=0.0223, X\left(\theta_{2}\right)=0.6854, X\left(\theta_{3}\right)=0.0591, \\
X\left(\theta_{4}\right)=0.0001, X(\Theta)=0.2326
\end{gathered}
$$

On the basis of this result, it is found that the evidence generally supports the paper as "good" level.

\section{CONCLUSION}

This paper makes a research on the evaluation of the graduate thesis. The evaluation of the graduate thesis is essentially a multi attribute group decision making problem. When there are differences in the evaluation opinions of the experts, how to use the overall evaluation results as the basis for the integration of the evaluation experts, and thus get the comprehensive evaluation results. This is a difficult problem and a key step in the evaluation of the degree thesis. It is directly related to the impartiality and the scientific nature of the evaluation results. This paper studies this problem from the perspective of evidence theory, and constructs a decisionmaking method.

\section{ACKNOWLEDGMENT}

Sponsored by:
(1) Project supported by the humanities and social sciences research youth fund of the China Ministry education, the project number: 16YJC790052

(2) Hunan province "The 13th Five-year" education planning project" School-enterprise cooperation in personnel training Virtual Alliance: organizational structure, resource sharing and performance assessment study" (project number: XJK015BGD053).

(3) 2015 Hunan Province Philosophy and Social Science Fund Project " Research on the Internet Media Effect China's Stock Market and Network Public Opinion Monitor Index of Listed Companies" (project number: 14YBA306).

(4) Supported by the constructing program of the key discipline of Finance in Huai-hua University.

\section{REFERENCES}

[1] Qiu Geng-xiang, Gong Yao-teng, Wang Jun. Research and Practice on the evaluation method of the thesis of master's degree students [J]. China higher education research, 2004, (3): $30-32$.

[2] Ma Liping. Construction of the quality evaluation system of graduate degree thesis [J]. Journal of Tianjin University of Technology, 2005,21 (6): $85-88$

[3] Wang Lei, Cai Zhi-qin, Wang Dian-long, Yang Guanghui, Wang Delun, Teng Hong Fei. Thesis evaluation system [J]. Journal of Dalian University of Technology (SOCIAL SCIENCE EDITION), 2003,24 (2): $15-20$.

[4] Li Zheng-hang, Mao Xu-dong, Liu Wan-ke, Chen Kai. The evaluation index system of the quality of doctoral degree studies [J]. Hubei University of Economics (SOCIAL SCIENCE EDITION), 2006,3 (7): $179-180$.

[5] Tang Wei-dong, Li Gang, Lin Yong, Zhang Bo. The evaluation program of the National Excellent Doctoral Dissertation $[\mathrm{J}]$ degree and postgraduate education, 2000, (1): 62 - 60 .

[6] Guan Zhimin,Shu Jun-yi, Ma Qinhai. Multi level fuzzy comprehensive evaluation model and its application in the quality of degree thesis [J]. scientific research management, 2005,26 (3): 153 - 157.

[7] Shen Yushun. Research on the evaluation method of the quality of graduate thesis: [J]. Chinese higher education evaluation, 2000, (2): 39 36.

[8] Zhang Qing-yue, Li Hong-tao, Zhao Jia-fa. A comprehensive evaluation on the quality of master's degree thesis 1998,22 Journal of Hebei Normal University (NATURAL SCIENCE EDITION) [J]. (3): 428 - 432.

[9] Xiao Wei. Reflections on the issue of justice in the evaluation of graduate students' degree thesis [J]. Degree and Graduate Education, 2006, (2): 33 - 32.

[10] Zhu Wei-dong, Hu Yun-yun. Research on the comprehensive evaluation of the leader of the state owned enterprise based on the theory of evidence [J]. China Management Science (Album), 2005, (13): $494-$ 498 